\title{
Bacterial Agents Associated With Acute Diarrhoea In Under-5 Children In Enugu, Nigeria.
}

\author{
${ }^{1}$ Dr Fc Korie, ${ }^{2}$ Dr An Ikefuna, ${ }^{3}$ Prof Bc Ibe \\ Departments of Paediatrics ${ }^{1}$ Federal Medical Centre, Umuahia, Abia State, Nigeria, ${ }^{2,3}$ University of Nigeria \\ Teaching Hospital, Enugu.
}

\begin{abstract}
Background: Diarrhoea continues to be the scourge of children across the world. Despite efforts by the World Health Organisation and other agencies, much still remains to be done in combating diarrhoeal diseases in the developing world, including Nigeria.

Objectives: To determine the bacterial agents of diarrhoea in under-5 children and their antibiotic sensitivity patterns.

Subjects and Method: One hundred and seven-four children below five years of age with diarrhoea and a similar number as controls were recruited for the study between June 2005 and May 2006 at the University of Nigeria Teaching Hospital, Enugu, Nigeria. Their socio-demographic factors such as age, sex, breastfeeding status, parents' occupation/education, were obtained.

Their stool samples were examined macroscopically and microscopically. Stool cultures and sensitivity tests were performed.

Results: Enteropathogenic E. coli was identified in $41.4 \%$ of the stool samples. There was no statistically significant difference in breastfeeding between the subjects and controls $(p>0.05)$. The age and sex distribution of the subjects with positive stool culture were not statistically significant $(p>0.05)$ when compared with those with negative cultures. Blood in stool was significantly associated with positive stool culture ( $p=0.0112$ ).

Drugs that can be useful in the empirical treatment of diarrhoea due to enteropathogenic Escherichia coli are gentamycin, amoxicillin-clavulanate, ciprofloxacin and cefuroxime.

Conclusion: Enteropathogenic E. coli is a significant bacterial agent in diarrhoea in childhood. Improvement in breastfeeding, socioeconomic and nutritional status will lead to a reduction in the incidence of diarrhoea due to bacterial pathogens.

Key Words: Acute diarrhoea; Under-5; Sociodemographic factors; pathogens.
\end{abstract}

\section{Introduction}

Diarrhoea has been defined as a change in bowel habit from normal with an increase in stool volume and/or fluidity with or without an increase in stool frequency. ${ }^{1}$

Diarrhoeal diseases are one of the leading causes of morbidity and mortality in children worldwide. The problem is serious in tropical countries where it is responsible for more than half the deaths in children under one year of age, and over 1.3 million deaths in children below 5 years of age. ${ }^{2,3}$

Diarrhoea cuts across all ages. ${ }^{4}$ Young children between the ages of 6-24 months, and those of lower socioeconomic status are the most commonly and severely affected. ${ }^{4}$ Breastfeeding provides significant protection against diarrhoea in infancy. ${ }^{5}$ Malnutrition predisposes to high transmission of diarrhoea. ${ }^{6}$

Bacterial pathogens are important causes of diarrhoea in children, particularly in developing countries where standards of personal and community hygiene are low. ${ }^{7}$

\section{Subjects And Methods}

The study was carried out at the University of Nigeria Teaching Hospital Enugu, Nigeria, a referral tertiary health facility. One hundred and seventy-four under-5 children with diarrhoea and a similar number of children as controls were recruited consecutively as they presented to the health facility from June 2005 to May 2006. The controls were matched for age, sex, socioeconomic and nutritional status.

A pretested questionnaire was used to obtain information on the age, sex, anthropometry, breastfeeding status, occupational/educational status of the parents.

The social class was determined using classification of social class as proposed by Oyedeji. ${ }^{8}$ This classification used the parental occupation and educational attainment to determine the social class.

The nutritional status was determined using the modified Wellcome classification. ${ }^{9}$

Approval was obtained from Hospital Ethical Committee. Informed written consent was obtained from the parent or caregiver. 
Clinical examination was performed on the subjects and controls. Five randomly selected stool samples were examined by the researcher and the Laboratory Scientist independently. The results were compared to ensure reliability. The Kappa score was 0.80 .

Stool samples were collected from the patients. Samples were collected in clear wide-mouth universal containers and sent immediately to a registered medical laboratory scientist or kept in an insulated box with icepacks until processing (within 6-8 hours of collection).

All stool specimens were analyzed following the standard methods of stool examination. ${ }^{10}$ These included the following:

1. Macroscopy: Gross appearance of the stool was noted especially consistency, presence of mucus and blood.

2. Microscopy: A small portion of each stool was suspended in saline and then examined microscopically for pus cells and red blood cells.

3. Bacteriology: All stool samples in liquid form were inoculated directly, whereas formed stools from the controls were first suspended in sterile normal saline solution and then inoculated.

Primary isolation of the bacteria was performed using MacConkey agar and Desoxycholate citrate agar media and selenite-f enrichment medium. Each plate was subsequently incubated at $37^{\circ} \mathrm{C}$ for $18-24$ hours, and then Gram-stained.

All isolates were characterized biochemical following conventional procedures. ${ }^{10}$ The antimicrobial susceptibility testing was done using disc-diffusion method. ${ }^{11}$

Analysis of data was carried out using the Statistical Package for the Social Sciences software. The patients were grouped according to age, sex, nutritional status, socioeconomic status, breastfeeding status, bacterial isolates, etc. The Chi-squared and Fisher's exact probability tests were used where appropriate. ${ }^{12}$

A probability (p) value of $<0.05$ was considered significant. Results were presented in tables.

\section{Results}

Between $1^{\text {st }}$ June, 2005 and $31^{\text {st }}$ May, 2006, a total of 392 children were seen. Of these, 19 could not be matched for age and sex, while 25 were rejected due to incomplete data in their questionnaires. Ultimately, 348 children aged 2 to 59 months were studied with 174 serving as subjects and 174 as controls.

\section{Age distribution of the children according to bacterial isolates}

Table 1 shows the age distribution of children with acute diarrhoea according to bacterial isolates. These comprised children with positive stool culture, and those with negative stool culture. Among those with positive culture, the age group 2-24 months accounted for $63 \%$ of the total bacterial isolates.

TABLE I: AGE DISTRIBUTION OF CHILDREN WITH ACUTE DIARRHOEA

\begin{tabular}{ccccc}
\hline & $\begin{array}{c}\text { Subjects with } \\
\text { Positive Stool } \\
\text { Culture }\end{array}$ & $\begin{array}{c}\text { Subjects with } \\
\text { Negative Stool } \\
\text { Culture }\end{array}$ & Total & \\
(months) & No \% & No \% & No \% & p-value \\
\hline $2-12$ & $30(41.7)$ & $47(46.0)$ & $77(44.2)$ & 0.718 \\
$13-24$ & $16(22.2)$ & $22(21.6)$ & $38(21.8)$ & 0.918 \\
$25-36$ & $13(18.1)$ & $20(19.6)$ & $33(19.0)$ & 0.797 \\
$37-48$ & $7(9.7)$ & $6(5.9)$ & $13(7.5)$ & 0.342 \\
$>48$ & $6(8.3)$ & $7(6.9)$ & $13(7.5)$ & 0.716 \\
\hline Total & $\mathbf{7 2 ( 1 0 0 . 0 )}$ & $\mathbf{1 0 2}(\mathbf{1 0 0 . 0})$ & $\mathbf{1 7 4 ( 1 0 0 . 0 )}$ & \\
\hline
\end{tabular}

Sex distribution of children with acute diarrhoea

More males had a positive stool isolates compared to the females, though the difference is insignificant $\left(\chi^{2}\right.$ $=0.019, \mathrm{p}=0.88$ ), table II.

\section{Stool frequency in children with acute diarrhoea}

Table II shows the distribution of stool frequency in children with acute diarrhoea. $43 \%$ of those with positive culture had stool frequency of five or less, and $57.0 \%$ had stool frequency of six or more. Among those with negative culture, $45.1 \%$ had stool frequency of five or less, and $54.9 \%$ had stool frequency of six or more. When the two groups are compared, the difference was not statistically significant $\left(\chi^{2}=0.071, p=0.789\right)$. 
Antibiotics treatment prior to hospitalization in children with diarrhoea

Table II shows the distribution of antibiotics treatment prior to hospitalization in children with acute diarrhoea. It shows that of those with positive stool culture, $34.7 \%$ received antibiotics and $65.3 \%$ did not receive antibiotics. Among the negative group, $40.2 \%$ received antibiotics and $59.8 \%$ did not receive antibiotics. When the two groups are compared, the difference is not statistically significant $\left(\chi^{2}=0.537\right.$, $\mathrm{p}=0.464)$.

TABLE II: SEX, STOOL FREQUENCY AND ANTIBIOTICS USE IN CHILDREN WITH DIARRHOEA

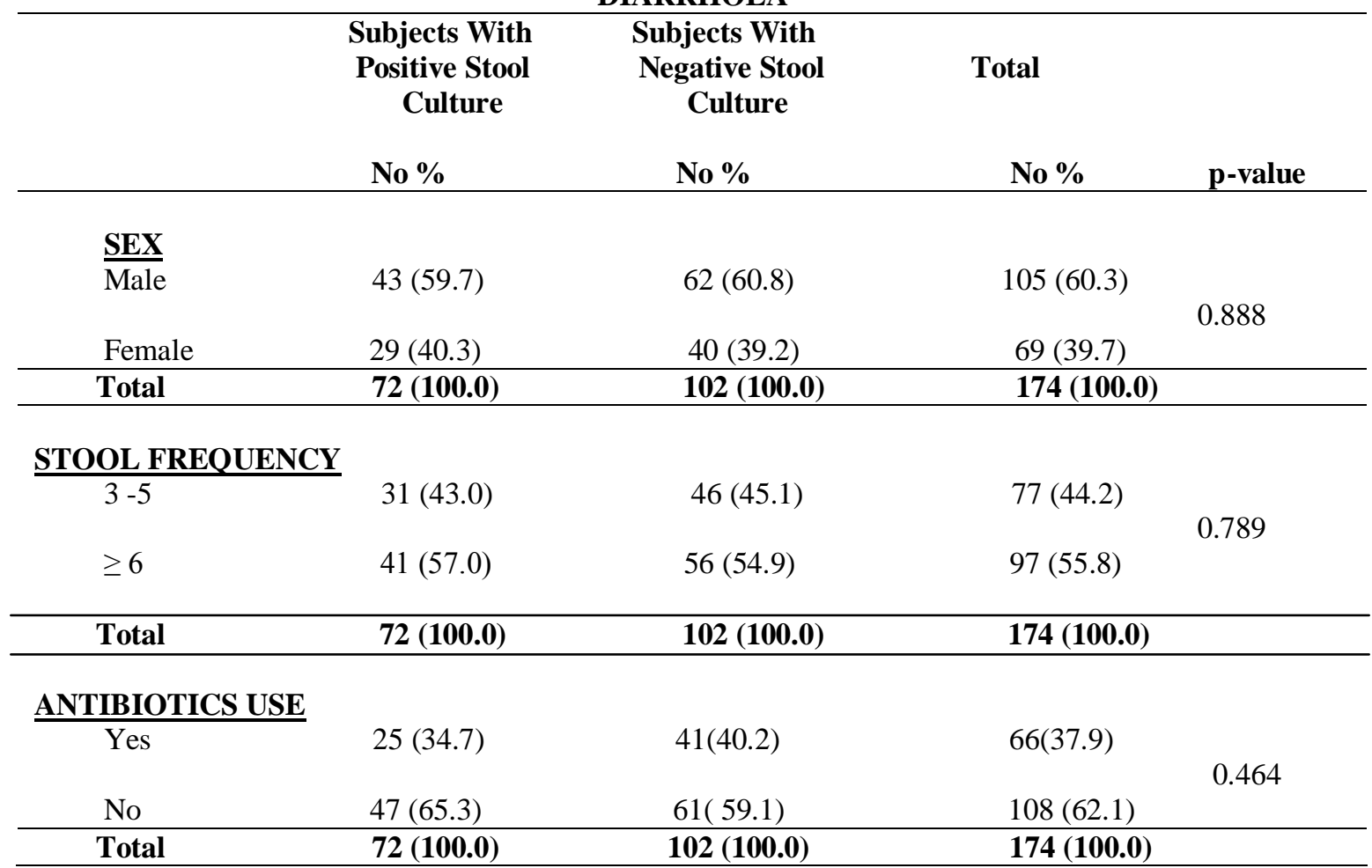

Total

Distribution of fever in children with acute diarrhoea

Table III shows the distribution of fever in children with diarrhoea. Among those who had positive stool culture, $72.2 \%$ had fever, while $27.8 \%$ did not have fever. In the group with negative culture, $72.5 \%$ had fever, while $27.5 \%$ did not have fever. When the two groups are compared, the result is not statistically significant $\left(\chi^{2}=0.0023, \mathrm{p}=0.962\right)$.

\section{Distribution of mucus in stool in children with diarrhoea}

Table III shows the distribution of mucus in the stools of children with acute diarrhoea. From the children with positive stool culture, $36.1 \%$ had mucus in their stools, and $63.9 \%$ did not have mucus in stool. Among the group with negative stool culture, $47.1 \%$ had mucus in the stool, while $52.9 \%$ did not have mucus in the stool. When the two groups of children are compared, the difference is not statistically significant $\left(\chi^{2}\right.$ $=2.070, \mathrm{p}=0.150$ ).

\section{Distribution of blood in stool in children with diarrhoea}

Table III shows the distribution of blood in the stools of children with acute diarrhoea. Bloody stool was observed in $6.9 \%$ of the subjects with positive culture, and absent in $93.1 \%$. All (100\%) of the children with negative culture had no blood in stool. When those with positive culture are compared with their counterparts, the difference was statistically significant $(\mathrm{p}=0.0112)$. 
TABLE III: DISTRIBUTION OF FEVER AND MUCUS/ BLOOD IN STOOL IN CHILDREN WITH ACUTE DIARRHOEA

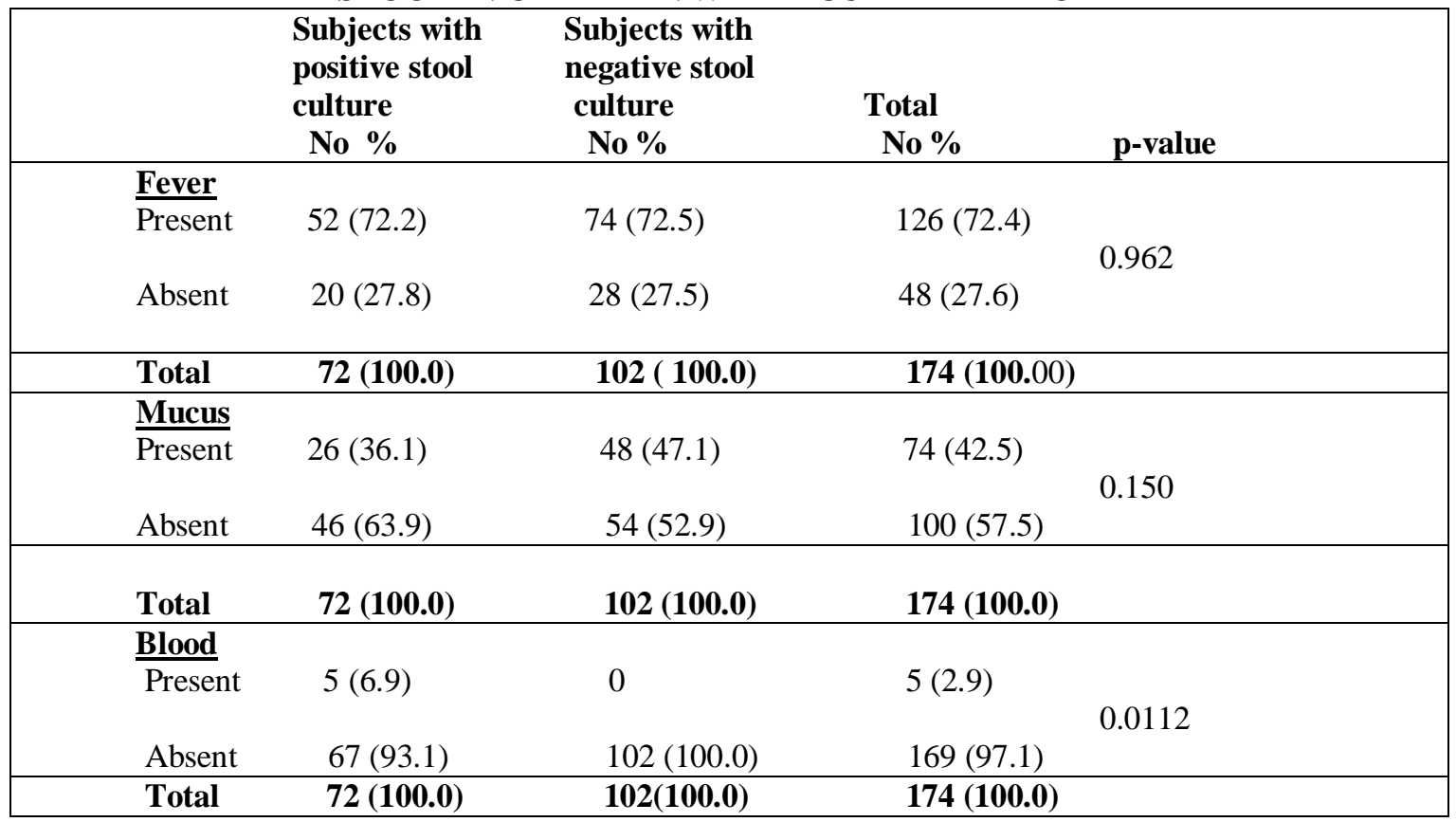

\section{Isolation of Enteropathogens}

A total of $72(41.4 \%)$ of the diarrhoeal stools contained recognizable enteropathogens compared with only $2(1.2 \%)$ in the control group. The bacterial agent isolated from the study in both the subjects and controls was enteropathogenic strains of $E$. coli.

\begin{tabular}{lcc} 
TABLE IV: & ISOLATION OF ENTEROPATHOGENS \\
\hline Bacteria & Subjects \% & Controls \% \\
\hline & $(\mathrm{n}=174)$ & $(\mathrm{n}=174)$ \\
Enteropathogenic & $72(41.4)$ & $2(1.2)$ \\
E. coli & 0 & 0 \\
Shigella & 0 & 0 \\
Salmonella & 0 & 0 \\
Campylobacter & 0 \\
\hline
\end{tabular}

Antibiotic sensitivity pattern

Table V shows the antibiotic sensitivity pattern of enteropathogenic E. coli isolates. Fifty-three (73.6\%) of the 72 bacterial isolates tested were susceptible to gentamycin, $47(65.3 \%)$ to amoxicillin-clavulanate, $44(61.1 \%)$ to ciprofloxacin, and cefuroxime, $39(54.2 \%)$ and $34(47.2 \%)$ to cotrimoxazole and amoxicillin, respectively. The resistance to chloramphenicol was $72.2 \%$, and ampicillin and tetracycline, which recorded $100 \%$ resistance each. Nineteen $(26.4 \%)$ were resistant to gentamycin, 25 (34.7\%) to amoxicillin-clavulanate and $28(38.9 \%)$ resistance was to ciprofloxacin and cefuroxime.

TABLE V: ANTIBIOTICS SENSITIVITY PATTERN OF ENTEROPATHOGENIC E. COLI

\begin{tabular}{lcc}
\hline Antibiotics & Sensitivity & Resistance \\
\hline & $n(\%)$ & $n(\%)$ \\
Gentamycin & $53(73.6)$ & $19(26.4)$ \\
Amoxicillin-claxulanate & $47(65.3)$ & $25(34.7)$ \\
Ciprofloxacin & $44(61.1)$ & $28(38.9)$ \\
Cefuroxime & $44(61.1)$ & $28(38.9)$ \\
Cotrimoxazole & $39(54.2)$ & $33(45.8)$ \\
Amoxicillin & $34(47.2)$ & $38(52.8)$ \\
Cephalexin & $26(36.1)$ & $46(63.9)$ \\
Ofloxacin & $25(34.7)$ & $47(65.3)$ \\
Chloramphenicol & $20(72.8)$ & $52(72.2)$ \\
Ampicillin. & 0 & $72(100.0)$ \\
Tetracycline & 0 & $72(100.0)$ \\
T & &
\end{tabular}




\section{Discussion}

Acute diarrhoea is one of the leading causes of morbidity and mortality in children worldwide, especially in tropical countries where it is responsible for more than half the deaths in children under one year of age. $^{2}$ In this study, the highest frequency of culture positive diarrhoeal cases were among the subjects in the age group 2-12 months, and the 13-24 months age groups, and this is similar to reports by other authors. ${ }^{4,13,14}$ This may be explained by the fact that at this stage, the children have started to move about and they put contaminated objects into their mouth.

The age range 37-59 months had the lowest frequency of bacterial isolates in this study. This is probably because of less tendency to put contaminated objects into the mouth-a finding similar to that of Oni and colleagues. ${ }^{15}$

There was a higher percentage of stool positivity among males than females. This was in agreement with the study of Coker et $\mathrm{al}^{16}$ in Lagos, and Jinadu et $\mathrm{al}^{4}$ in Ondo State. This may be due to the fact that males are generally more active than females, and therefore are more likely to pick particles from the ground and put into their mouth.

Eighty-two $(47.1 \%)$ of the total population of the subjects in the present study were in the lower social class group (class IV-V). Oyedeji in a study of the socio-economic and cultural background of children in Ilesha, Nigeria reported that $65 \%$ of their own patients were in the lower social class (IV-V). The preponderance of the subjects from the lower socio-economic class in the present study therefore is in agreement with the pattern observed in Ilesha. ${ }^{8}$ This group is more likely to have poor water supply, poor personal hygiene, improper food preparation, poor weaning practices and overcrowding which predispose to high rate of transmission of diarrhoea. ${ }^{17}$

The highest case of diarrhoea was among those who used tap water (40.9\%), followed by water tanker(26.4\%), well water (12.6\%) and borehole (9.2\%). The relatively low case of diarrhoea in those who used well water agrees with work done in Mali by Plate et al. ${ }^{18}$

Also among the subjects with positive culture, $34.7 \%$ received antibiotics and $65.3 \%$ did not receive antibiotics. The increased frequency of diarrhoea among those who took antibiotics may be as a result of antibiotics-associated diarrhoea. Similarly, the smaller percentage of stool culture in those who took antibiotics may be due to the fact that antibiotics can inhibit the growth of bacteria and give a false-negative result. ${ }^{19}$ From this study, the rate of use of antibiotics was between 59.8\%-65.3\%. This is almost similar to a study by Oni et $\mathrm{al},{ }^{15}$ who found a rate of $54.5 \%$.

In the study, there was a higher rate of diarrhoea with positive stool culture among children who were not breast-fed compared to those who were breast-fed. This finding is in keeping with a previous study. ${ }^{5}$ It is known that breastfeeding provides a significant protection against diarrhoeal disease. ${ }^{5}$ Breastfed children however, can have diarrhoea usually from lack of exclusive breastfeeding, or when they put contaminated objects into their mouth. This may have accounted for the high rate of diarrhoea even among the breastfed children, as in a previous study. ${ }^{15}$ Fever was found in $72.2 \%$ of the subjects with positive stool culture and $72.5 \%$ of the subjects with negative culture. This is similar to previous studies, ${ }^{20,21}$ which recorded $73.6 \%$ and $74.5 \%$ respectively. Mucus was seen in $36.1 \%$ of those with positive stool culture. This is similar to the study by Alabi et al. ${ }^{20}$

Bloody stool was seen in $6.9 \%$ of the subjects. This is also similar to a previous study, ${ }^{14}$ which noted that $10 \%$ of diarrhoea cases had blood in stool. Stool frequency of 3-5 times was found in $43 \%$ of the subjects with positive stool culture, and a frequency of six times or more was seen in $57.0 \%$ of the subjects with positive culture. There was no statistical significant difference between these and their counterparts with negative stool culture.

Bacterial pathogen was identified in $72(41.4 \%)$ of the subjects, with as high as $58.6 \%$ yielding no recognizable enteropathogens. The particular strain of the bacteria identified was the enteropathogenic strain of $E$. coli. This is in consonance with previous studies ${ }^{22-24}$ which observed that enteropathogenic strain of $E$. coli was the commonest cause of diarrhoea in children less than 5 years of age. The high rate of antibiotic use could have suppressed the growth of other bacteria as it is known that premedication with antimicrobial agents can give rise to false-negative laboratory tests. ${ }^{23-24}$ Again other enteropathogenic agents other than bacteria could have been responsible for the diarrhoea in the remaining $61.5 \%$ of the subjects.

The antibiotics sensitivity pattern shows high sensitivity to gentamycin, amoxicillin-clavulanate, ciprofloxacin and cefuroxime. The sensitive to gentamycin here is similar to a previous study, ${ }^{20}$ which recorded a high sensitivity to gentamycin. Workers at Kenya, ${ }^{25}$ Uganda, ${ }^{26}$ and also in Nigeria, ${ }^{27-30}$ have found a high resistance to ampicillin which is in agreement with findings in this study.

The high rate of isolation of $E$. coli in Enugu is a pointer to the fact that this organism still plays a significant role in acute diarrhoea. Preventive and control measures to reduce the incidence of diarrhoea should be adopted. These include improvement in personal and environmental hygiene. Sewage and refuse disposal methods should be improved upon. There is need to provide safe potable water. 
Finally, the use of oral rehydration therapy in the management of acute diarrhoeal disease should be encouraged. This has helped in the prevention and correction of dehydration due to diarrhoea.

\section{References}

[1] Al-Jurayyan NA, Al-Nasser MN, Al-Rashed AM, et al. Management of acute childhood diarrhoea in Saudi Arabia: Practices versus the WHO recommendations. East Afr Med J 1994;71:110-12.

[2] Amardeep T. Diarrhoea in the Dominican Republic: Determinants of the utilization of children's Health Service. J Trop Pediatr 2003; 49:93-5.

[3] Ahmed IS, Eltom AR, Karrar ZA, et al. Knowledge, attitudes and practices of mothers regarding diarrhoea among children in a Sudanese rural community. East Afr Med J 1994;71:716-7.

[4] Jinadu MK, Olusi SO, Agun JI, Fabiyi AK. Childhood diarrhoea in rural Nigeria. Studies on prevalence, mortality and socioenvironmental factors. J Diarrhoeal Dis Res 1991; 9:323-7.

[5] Morrow AL, Ruiz-Palacios GM, Altaye Mekibib, Jiang X, Goprerrero ML, Meinzen-Derr JK, et al. Human Milk Oligosaccharides are associated with protection against diarrhoea in breast-fed infants. J Pediatr 2004; 145: 297 - 303.

[6] Richard LG, John BS, Jay FM, Maria AS. Diarrhea as a Cause and an Effect of Malnutrition: Diarrhoea Prevents Catch-up Growth and Malnutrition Increases Diarrhea Frequency and Duration. Am J Trop Med Hyg 1992;47:28-35

[7] Ibe BC, Onyemelukwe N. Enteropathogenic Escherichia coli and infantile diarrhea in Enugu. Orient J Med 2001;13:6-8

[8] Oyedeji GA. Socioeconomic and cultural background of hospitalized children in Ilesha. Nig J Paediatr 1985;12:111-17.

[9] Hendrickse RG. Protein Energy Malnutrition. In:Hendrickse RG, Barr DGD, Matthews TS, eds. Paediatrics in the Tropics, 1st Ed. Oxford: Blackwell Scientific Publications,1991:119-31.

[10] Cowan ST. In: Cowan ST, Steel KJ, eds. Manual for the identification of medical bacteria. $3^{\text {rd }}$ ed. Cambridge: Cambridge University Press, 1974:

[11] National Committee for Clinical Laboratory Standards. Performance standards for antimicrobial disc susceptibility test. $7^{\text {th }}$ ed. Approved Nstandards document M2A7 Wayne P.O. USA 2000.

[12] Araoye MO. Research Methodology with Statistics for Health and Social Sciences Ilorin. Nathadex Publishers. $1^{\text {st }}$ Ed. 2003;160258 .

[13] Ibe BC, Onyemelukwe NF. Campylobacter enteritis in children in Enugu. Nig J Coll Med 1998; 3:100-2.

[14] Adegunloye DV. Carrier rate of enteric bacteria associated with diarrhoea in children and pupils in Akure, Ondo State, Nigeria. Afr J Biotech 2006;5:162-4.

[15] Oni GA, Schumann DA, Oke EA. Diarrhoeal disease morbidity, risk factors and treatment in a low socioeconomic area of Ilorin Kwara State, Nigeria. J Diarrhoeal Dis Res 1991;9:50-7.

[16] Coker AO, Adefeso AO. The changing pattern of Campylobacter jejuni/coli in Lagos, Nigeria after 10 years. East Afr Med J 1994;71:437-9.

[17] Erku WA, Ashenafi M. Prevalence of food borne pathogens and growth potential of Salmonella in weaning food from Addis Ababa Ethiopia. East Afr Med J 1998;75:215-7.

[18] Plate DK, Strassman BI, Wilson ML. Water sources are associated with childhood diarrhoea prevalence in rural east-central Mali. Trop Med Int Health 2004;9:416-25.

[19] D'Agata EM, Gautam S, Green WK, Tang YW. High rate of false-negative results of the rectal swab culture method in detection of gastrointestinal colonization with vancomycin-resistant enterococci. Clin Infect Dis 2002;34:167-72.

[20] Alabi SA, Audu RA, Oyedeji KS. Viral, bacterial and parasitic agents associated with infantile diarrhoea in Lagos. Nig J Med Research 1998;2:29-32.

[21] Omoigberale AI, Abiodun PO. Prevalence of Yersinia enterocolitica among diarrhoeal patients attending UBTH, Benin City, Nigeria. Sahel Med J 2002;5:182-5.

[22] Akinyemi KO, Oyefolu AO, Opere B. Otunba-Payne VA, Owuru AO. Escherichia coli in patients with acute gastroenteritis in Lagos, Nigeria. East Afr Med J 1998;75:512-15.

[23] Ogunsanya TI, Rotimi VO, Adenuga A. A study of the aetiological agents of childhood diarrhoea in Lagos, Nigeria. J Med Microbiol 1994;40:10-4.

[24] Agbonlahor DE, Odugbemi TO. Enteropathogenic, entero-toxigenic and enteroinvasive Escherichia coli isolated from acute gastroenteritis patients in Lagos, Nigeria. Trans R Soc Trop Med Hyg 1982;76:265-7.

[25] Kariuki S, Gilks C, Batchelor B. Antimicrobial susceptibility and presence of extra chromosomal DNA in Salmonella and Shigella isolates from patients with AIDS. East Afr. Med. J 1994;71:292-6.

[26] Legros D, Ochola D, Lwanga N. Antibiotic sensitivity of endemic Shigella in Mbarara, Uganda. East Afr Med J 1998;75:160

[27] Olukoya DK, Oni O. Plasmid profile analysis and antimicrobial susceptibility patterns of Shigella isolates from Nigeria. Epidemiol Infect 1990;105:59-64.

[28] Eko FO, Utsalo SJ. Antimicrobial resistance trends of shigella isolates from Calabar, Nigeria. J Trop Med Hyg 1991;94:407-10.

[29] Olukoya DK, Ogunjimi AA, Abaelu AM. Plasmid profiles and antimicrobial susceptibility patterns of Vibrio cholera 01 strain isolated during a recent outbreak in Nigeria. J Diarrhoeal Dis Res 1995;13:118-21.

[30] Olukoya DK, Daini O, Alabi SA, Coker AO, Odugbemi T, Akirimisi EO. Antimicrobial resistance patterns and plasmids of enteropathogenic Escherichia coli isolated in Nigeria. Eur J Epidemiol 1998;4:306-9. 